\title{
El protesto notarial
}

Rolando Castellares Aguilar

Abogado por la Universidad Mayor de San Marcos.

Postgrado en Ciencias Administrativas y en Banca y Finanzas por la Facultad de Economía de la Universidad de Roma. Profesor Universitario de Derecho Bancario. Miembro de la Comisión Redactora del Proyecto de la Ley de Títulos Valores.

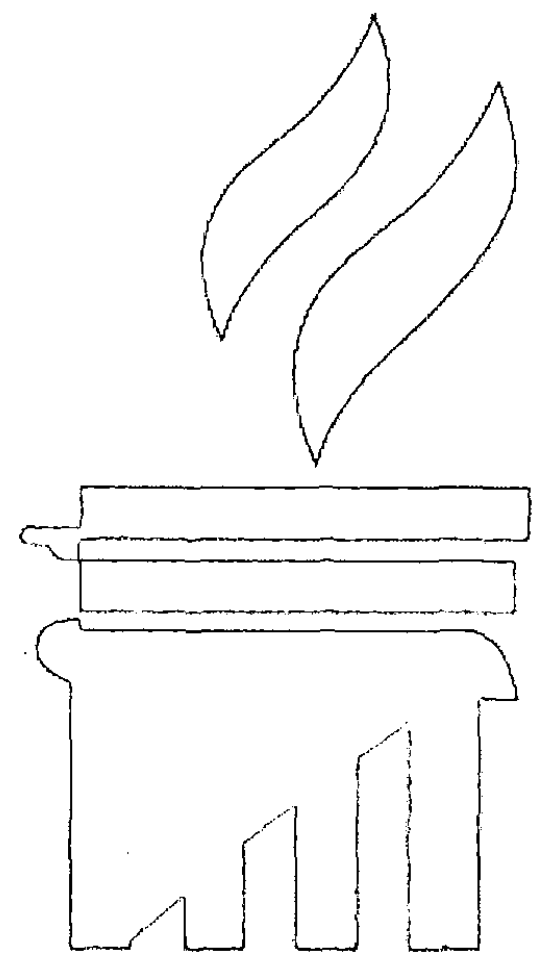

Aun cuando la actual Ley de Títulos Valores ya tiene más de ocho años de vigencia, se mantienen aún dudas sobre el plazo para realizar el protesto notarial de los títulos valores, como consecuencia de la confusión en la que algunos sectores incurren, al concebir el actual procedimiento del protesto con aquel que contenía la derogada Ley 16587.

Al respecto, abordaremos en esta oportunidad este tema en particular, concluyendo que los plazos previstos para el protesto en la actual Ley 27287 , se refieren a plazos para cursar la notificación del protesto al deudor, y no a la fecha o plazo para devolver el título protestado al interesado que lo solicitó.

El protesto, es una institución jurídica muy antigua y ligada más bien al Derecho Cambiario, 
mediante el cual lo que se persigue es demostrar en forma fehaciente y formal, el incumplimiento de alguna obligación contenida en un título valor que a la postre se ha resumido en la falta de pago y, en el caso de la Letra de Cambio, además, en su falta de aceptación. Estas son las dos clases de protesto que prevé la legislación peruana: por falta de pago y por falta de aceptación.

Así, en principio, hay dos fundamentos básicos que sustentan el protesto. El de autenticidad y el de solemnidad a los que por nuestra parte podemos agregar el de publicidad, que a la postre se ha convertido en una de las más importantes funciones del protesto. Decimos en principio, porque en cuanto a la solemnidad, tanto en el procedimiento que se sigue como en la obligatoria intervención de una autoridad que dé fe de tal incumplimiento, se ha venido flexibilizando en los últimos años y en las recientes corrientes jurídicas doctrinarias, al dar la posibilidad que la labor del fedatario no necesariamente deba ser realizada por la autoridad o funcionario de fe, sino que pueda ser sustituida por un tercero que no lo es, tal el caso de bancos u otras empresas del sistema financiero, como viene ocurriendo en la legislación nacional y comparada, desde ya hace muchos años.

Así, por ejemplo, en el Perú tenemos el caso del cheque, que desde hace mucho tiempo tiene un sistema alternativo al protesto para dejar evidencia cierta del incumplimiento en su pago, procedimiento que últimamente se ha extendido a todos los títulos valores que representando obligación de pago dinerario a través de cargos en una cuenta bancaria, no sean cumplidos por el deudor. Otro ejemplo de esta flexibilización de la autenticidad y solemnidad es el hecho de admitir que el acto o diligencia del protesto se encargue a un secretario, auxiliar o persona de apoyo del funcionario o autoridad de fe, denominados en el caso de la legislación peruana, como "secretarios notariales", que reemplazan en esa labor al notario, quien queda relevado de cumplir dicha labor en forma personal, como toda otra función notarial.
$Y$ es que el principio de autenticidad, que conlleva la necesaria intervención del notario o funcionario de fe, ha devenido en impracticable por la misma realidad del incremento y uso masivo de los títulos valores en la actividad comercial cada vez más amplia y difundida, por lo que igualmente se ha flexibilizado la solemnidad, como podremos apreciar de los cambios que se han introducido en la nueva Ley de Títulos Valores, eliminándose actas y actos sumamente rígidos que antes existian, sustituyéndolos por procesos y trámites simples, preservando de ese modo la esencia y finalidad que tiene el protesto de dejar constancia fehaciente, cierta, y confiable que el deudor requerido ha incurrido en mora, situación que se publicita en el mercado como una información de sumo interés para los demás agentes que quedan advertidos de la solvencia del moroso.

A pesar de esta finalidad que en esencia cumple el protesto, ha sido y sigue siendo muy criticado, debido a que en las relaciones comerciales la mora es automática, por lo que no debería requerir de acto o trámite alguno para constituir al deudor incumplido en mora y publicitar tal situación a través de las centrales de riesgo. Sin embargo, los defensores del protesto señalan que ello es necesario por los efectos que genera tal mora incurrida en obligaciones representadas por un título valor, que dará lugar al ejercicio de acciones cambiarias que son sumarísimas, por lo que debe contarse con elementos ciertos $y$ confiables que merezcan y justifiquen estos procesos ejecutivos. Las posiciones son pues sustentables por ambas partes $y$, el hecho es que en la legislación peruana se ha preferido mantener el protesto, con facultad de prescindir de él solo previo pacto con el deudor principal del título valor y constancia literal del pacto que conste en el mismo título valor.

Las leyes anteriores a la vigente, como son el Código de Comercio y la Ley 16587, regulaban el protesto como un acto o diligencia sumamente formal y solemne, que debía ser cumplido por el Notario (o por el Juez de Paz en las plazas donde no había Notario), y preveían el levantamiento de actas en una diligencia única, con un contenido específico y detallado cuya inobservancia 
en su formalidad y solemnidad podían llevar a la nulidad del acto del protesto y el consiguiente perjuicio del título valor mal protestado, resultando esencial contar con el protesto regular para tener y mantener la acción cambiaria, aun cuando se hubiera textual y expresamente liberado de ello.

En efecto, el protesto debía ser diligenciado en un solo acto, en día hábil y antes de las 19:00 horas y, en el caso del Código de Comercio, hasta antes de "la puesta del sol" con retención hasta esa hora, debiendo constar en el acta que el Notario debía extender en un registro especial para protestos, cuyo contenido debía referirse al lugar, fecha, hora de la diligencia, nombre del solicitante como de la persona contra quien se dirigía el protesto, nombre de la persona con quien se entendía la diligencia, su respuesta o motivos de la falta de la persona a quien se dirigía el protesto, transcripción del título, y firma del Notario. ${ }^{2}$

Esta solemnidad y formalidad del protesto que caracterizaba a las normas derogadas ha llevado a revisar su utilidad y modificar su trámite, simplificándolo en la vigente Ley de Títulos Valores. Así, una de las formalidades impuesta por la ley anterior, era que el protesto debía obtenerse dentro de los 8 días siguientes al vencimiento del título valor (en el caso del protesto por falta de pago), y dentro del plazo de presentación de la Letra de Cambio para ese efecto (en el caso del protesto por falta de aceptación). ${ }^{3}$ Por la costumbre generalizada en el mercado peruano de lograr el protesto el octavo día, que era el último para hacerlo, a pesar que la ley señalaba que podía tramitarse en uno cualquiera de los 8 días siguientes al vencimiento, surgió la mala costumbre de creer que se contaba con un período de "ocho días de gracia", para pagar las deudas contenidas en títulos valores, congestionándose el último día (el octavo) para realizar el protesto, día último en el que por lo demás debía obtenerse el protesto antes de las 19:00 horas, pues a las 19:00 ya era tarde, extemporáneo y sin valor. Conocemos de un caso anecdótico de un Juez de Paz, amigo del deudor protestado, que demoró la diligencia del protesto y en el acta señaló que se había apersonado al domicilio del deudor, "(...) siendo las 19:00 horas (...)", lo que sirvió obviamente al moroso para deducir la nulidad del protesto, pidiendo la exhibición del acta del protesto, frustrando la acción ejecutiva que el acreedor había iniciado sobre la base de ese protesto, toda vez que el protesto debió haberse realizado ANTES de las 19:00 horas. Esta situación, de congestión de

1 Código de Comercio, artículo 493, disponía que cualquiera que hubiese sido la hora en que se hubiese realizado el protesto, el notario debía retener la letra de cambio en su poder, hasta la puesta del sol del día en que se hubiese hecho, pudiendo admitir entre tanto los pagos de cargo del aceptante, norma que se repite en el párrafo segundo de la Ley 16587, disponiendo que tal retención que debe hacer el notario, debe ser hasta las 19:00 horas.

2 Ley 16587, artículo 55.- El protesto constará en acta que el notario, o el Juez de Paz, debe extender en un registro especial para protestos, cuyas hojas podrán ser impresas con formularios para tal fin. Dicha acta contendrá los siguientes elementos:

Lugar, fecha y hora de la diligencia;

Nombre del solicitante;

Nombre de la persona contra quien se dirige el protesto;

Nombre de la persona con quien se entienda, y su respuesta o motivos de la falta de ésta;

Transcripción del título; y

Firma del Notario o del Juez de Paz o, en su caso, la del Secretario Notarial que efectúe la diligencia.

3 Ley 16587, artículo 49.- El protesto debe levantarse dentro de los siguientes términos:

Si se trata de protesto por falta de aceptación dentro del plazo de presentación de la letra para ese efecto.

Si se trata de protesto por falta de pago de letra, pagaré o vale a la orden, dentro de los ocho días posteriores al vencimiento.

Si se trata de protesto por falta de pago de cheque, dentro del plazo de presentación previsto por el artículo 165 , salvo que el tenedor opte por la comprobación autorizada por el artículo 170; y

En los demás títulos, dentro de los ocho días siguientes a la fecha en que debió cumplirse la respectiva obligación.

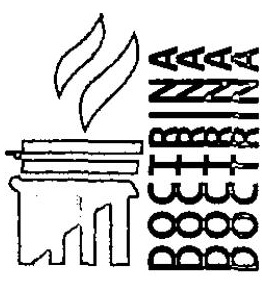


protestos en el último día, llevó a los Notarios a contar con secretarios notariales, incorporándose en la Ley 16587 la posibilidad de que un acto de fe notarial sea delegado a persona distinta al Notario, no existiendo número máximo de ellos, y siendo solo necesario recurrir a la respectiva Corte Superior para lograr tal designación, bajo responsabilidad del Notario. ${ }^{4}$

Pero aun esta medida no fue suficiente, resultando materialmente imposible que en un solo día, un Notario y aun con todos sus secretarios notariales, pudiese realizar el protesto de decenas o cientos de títulos valores que estaban en su último día para el protesto, cumpliendo con todas las formalidades impuestas por la ley. Esta realidad de imposibilidad material de cumplir con todas las formalidades que imponía la ley, llevó a la mayoría de los Notarios a limitarse a cumplir con las solemnidades de ley solo de modo formal o documental (solo en el título valor y actas) pero no en la realidad, lo que generó un descrédito y malestar en todos los sectores, como críticas sumamente ácidas en contra del protesto notarial y contra esta labor sin objeto y no real de los Notarios, denunciado hasta por ellos mismos ${ }^{5}$, generándose casos por demás anecdóticos como actas notariales levantadas por un mismo Notario el mismo día y en la misma hora, pero en lugares distantes uno del otro, o diligencias que supuestamente se realizaron en domicilios que eran inexistentes o viviendas derruidas o inhabitables, señalando sin embargo en el acta que la diligencia se realizó regularmente o se entendió con persona que se negó a identificar, o aquel caso muy recordado de protesto realizado en el Congreso de la República un día en el que había sido tomado por las Fuerzas Militares (golpe militar), por lo que tal acto era imposible que se haya podido cumplir; anulándose el protesto en todos esos casos al exhibirse las actas notariales.

Esta situación llevó al legislador del año 2000, a una profunda y saludable revisión de esta institución y de la formalidad que debería tener el protesto, cuya eliminación inclusive casi se logró concretar como consecuencia del régimen previsto en la anterior ley y siguiendo las recomendaciones de UNCITRAL, que postula el protesto solo voluntario y previo pacto. Así, según la actual Ley de Títulos Valores a la que le corresponde el número 27287, se concibe el protesto como un mero acto de notificación mediante la cual se "deja constancia" del requerimiento para que el obligado cumpla con la obligación representada por el título valor; objetivo que puede lograrse ya sea a través de

4 Ley 16587, artículo 51.- El protesto será diligenciado en un solo acto:

Por Notario o por un Secretario de éste (...)

Artículo 52.- Para los efectos del primer inciso del artículo anterior, la Corte Superior de Justicia del respectivo Distrito Judicial podrá designar, a propuesta del Notario y bajo la responsabilidad de éste, a uno de más Secretarios Notariales con autorización para diligenciar protestos.

5 Ley de Títulos Valores, Editorial Justo Valenzuela EIRL, Lima, 1986, FLORES POLO, Pedro: "En realidad, como el protesto no lo efectúan los Notarios ni sus secretarios, no se cumple la Ley ni se recibe ningún servicio pero debe pagarse su importe, lo que encarece injustificadamente el costo del crédito. No se consigue ninguna utilidad ni se cumple ninguna finalidad de orden práctico".

Revista OIGA, Notario Rafael CHEPOTE: "La única ventaja de estas disposiciones es la que tiene el Notario, quien puede cobrar honorarios sin intervenir para nada en los protestos de los Títulos Valores. Esto es más alarmante en el caso de los títulos valores de los bancos comerciales, cuya cantidad hace imposible la notificación al obligado, constituyendo una suculenta entrada para los Notarios que laboran en esas entidades. Creo, pues, que no hay otra salida que la modificación de la Ley de Títulos Valores en los dos últimos artículos señalados, 55 y 56, de otro modo se estaria contribuyendo a la prostitución del Notariado al amparo de la Ley, por un error de procedimiento".

Diario El Comercio, Notario CHANGANAQUÍ BRENT: "Sin peligro alguno y antes s bien con seriedad, economía de tiempo y gastos, el añejo formulismo del protesto debe ser sustituido por la constancia que en la misma letra de cambio ponga, con los requisitos que se juzgue convenientes, el Banco portador del titulo, ya sea por comisión de cobranza o por descuento, que aquella no ha sido aceptada o no ha sido pagada".

Citas que hace el Dr. FLORES POLO, Pedro. En: Comentarios a la Nueva Ley de Títulos Valores, Editorial Jurista, 2001, Primera Edición, p.186. 
la intervención de Notario o de Juez de Paz (en las plazas donde no hubiere Notario), o a través de las empresas del sistema financiero, en este último caso, mediante la "formalidad sustitutoria del protesto".

Así, el protesto no es más una diligencia formal, ni solemne, ni debe cumplirse en un solo acto y redactándose necesariamente un acta. El protesto ahora consiste en una mera notificación dirigida al deudor, hecha por conducto del funcionario de fe (Notario o Juez de Paz), con posibilidad de sustituir este trámite por la respectiva constancia de falta de pago total o parcial, en los casos de títulos valores pagaderos con cargo en una cuenta mantenida en una empresa del sistema financiero que, en estricto, no es protesto pero surte los mismos efectos de este.

Así, bajo este nuevo esquema del protesto (notificación), los plazos dentro de los cuales debe realizarse el protesto han sido ampliados, en modo tal que el Notario o, en su caso, el Juez de $\mathrm{Paz}$, cuenten con un período prudencial, breve pero suficiente, para cumplir con su cometido $y$ de ese modo se logre el objeto esencial que tiene el protesto, que como ya hemos señalado es generar la certeza que la persona contra quien se dirige es un deudor incumplido de deuda real, que podrá ser ejecutado por medios procesales sumarísimos, concediendo al deudor la oportunidad de evitar tal acción cambiaria ejecutiva pagando su deuda o señalando la falsedad del título, o de su firma $u$ otros alegatos que pueda oponer. Así, el plazo para protestar por falta de pago, por ejemplo, se ha ampliado de 8 a 15 días calendario, eliminándose así la concentración en un solo día para realizar tal notificación, que era el principal problema que se tenía con el régimen anterior.

Por ello debemos destacar el hecho de que no se trata de una simple ampliación de 8 a 15 días calendario; pues en ese caso, solo se habría iniciado la mala costumbre de imponer los" 15 días de gracia". Lo que se ha dispuesto es que de este plazo de 15 días que se estatuye para notificar el protesto, el interesado en obtenerlo tiene la obligación de presentar el título objeto de pro- testo al Notario, necesariamente dentro de los primeros 8 días. De ese modo, se ha logrado que el Notario cuente por lo menos con 7 (siete) días calendario, dentro de los cuales, podrá realizar la notificación del protesto encomendado. La seguridad de este sistema, de que el interesado haga entrega del título al Notario dentro de los primeros 8 días calendario, se logra disponiendo que tal entrega se registre y enumere, según relación y registro que el Notario está obligado a llevar correlativamente.

Para explicarnos aún más, con el actual régimen un título valor con fecha fija de vencimiento, por ejemplo, podría protestarse al día siguiente del vencimiento, día en el que el tenedor podría entregar el título al Notario y este dirigir la comunicación del protesto al deudor moroso en el mismo día y esperar hasta el día siguiente para que el moroso evite el protesto pagando, o señale alguna irregularidad que estime, con lo que estaríamos en el segundo día siguiente al vencimiento. De no ocurrir el pago hasta ese segundo día siguiente al vencimiento, el subsiguiente día (tercer día siguiente al vencimiento), el tenedor podrá ya contar con el título con la constancia del protesto consignado por el Notario, con indicación de la fecha en la que se cursó la notificación. Este proceso ejemplificado, sería el proceso más breve del protesto notarial.

En el otro extremo tendríamos la siguiente situación. Entrega del título al Notario el octavo día siguiente al vencimiento (último día para hacer esta entrega del título al Notario) y notificación del protesto por el Notario el día décimo quinto (último día para protestar que tiene el Notario), espera hasta el día siguiente a la notificación cursada (décimo sexto día siguiente al vencimiento), y devolución del título protestado por el Notario el sub siguiente día (décimo séptimo día siguiente al vencimiento). Este sería el plazo máximo ordinario de ley para lograr el protesto; pues pueden darse casos excepcionales de extender aún más este plazo, como referiremos más adelante.

Al respecto, han surgido ciertas dudas, a nuestro juicio totalmente infundadas y alejadas del texto expreso y del espíritu de la Ley, en el sentido 
que el título con la constancia de haber sido protestado debe ser entregado en devolución al interesado, como máximo, el décimo quinto día siguiente al vencimiento del título protestado; posición que está totalmente alejada de lo prescrito por la ley vigente, tal vez explicable por la confusión del actual procedimiento del protesto con el anterior proceso formal del protesto que preveía la derogada Ley 16587 , pues bajo tal criterio, el plazo para el protesto se habría fijado en trece (13) días, y la Ley vigente señala que "I a notificación relativa al protesto deberá cumplirse (...) dentro del plazo señalado en el artículo $72^{\prime \prime} ;$ y, este numeral dispone que "(...) el protesto debe realizarse (...) si se trata de protesto por falta de pago (...) dentro de los 15 (quince) días posteriores a su vencimiento $(\ldots)^{\prime \prime}$; agregando además que "una vez recibido el titulo valor objeto de protesto, el fedatario (Notario) REALIZARÁLANOTIFICACIÓN señalada en el articulo 77, DENTRODE LOS PLAZOS SENAALADOS EN EL PRESENTE ARTICULO". Así, no cabe duda alguna que es la NOTIFICACIÓN al deudor y no la DEVOLUCIÓN del título protestado al interesado, la que debe hacerse dentro de los plazos previstos en el referido Artículo 72 de la Ley de Títulos Valores.

Estos textos legales transcritos sumamente claros, resultan además coincidentes con lo sustentado por el legislador en la respectiva Exposición de Motivos de la Ley, documento en el que se señala que" (...) se propone modificar totalmente el proceso del protesto, sustituyéndolo por una notificación dirigida al obligado principal y de cuya realización dará fe el funcionario respectivo (Notario o Juez). De este modo se busca que el fedatario realice efectivamente dichas notificaciones de protesto, como hoy lo hace certificando la entrega de cartas y comunicaciones bajo su conducto, sea personalmente o en el caso de los Notarios a través de secretarios notariales que designe, terminando con esto, además, el actual debate acerca de la derogatoria tácita de la Ley 16587 -Ley de Títulos Valores-quepara algunos contendría la Ley 26002 - Ley del Notariado- al establecer que la función notarial es personal y exclusiva. Para un adecuado control, el fedatario llevará un registro en libros o medios electrónicos de las notificaciones dirigidas a los deudores requeridos, anotando las negativas de las firmas u obligaciones que pueda ser señalado por el requerido, pagos parciales u otros hechos vinculados al titulo materia del protesto, o la imposibilidad de cumplir con la notificación por contener una dirección inexistente, en cuyo caso la comunicación se dirigirá a la Cámara de Comercio Provincial del lugar de pago, lográndose con ellos todos los efectos del protesto".

"Del mismo modo, para que la labor del fedatario no se vea congestionada, se propone que esta notificación del protesto se efectúe dentro de los quince (15) dias siguientes al vencimiento del título objeto de protesto con obligación del tenedor del título valor de entregar el documento al fedatario dentro de los primeros ocho (8) dias como actualmente dispone la Ley de Títulos Valores, contando el fedatario con los siguientes dias, con ellímite de quince (15) dias antes señalados, para cumplir su cometido de notificar (...) Del mismo modo, tales notificaciones se deberán efectuar sólo de lunes a viernes y en dia hábil, eliminándose la limitación de la hora".

De lo antes transcrito, queda pues por demás claro que, es la notificación del protesto la que debe hacerse dentro de los plazos fijados para cada caso en el artículo 72 de la Ley, tales plazos no se refieren al plazo para hacer devolución del título ya protestado con la anotación "Documento Protestado", devolución que proceda hacer al subsiguiente día de la notificación ${ }^{8}$, "(...) con indicación de la fecha en que se cursó la notificación, refrendada con su firma" (del

6 Ley 27287 , artículo 75.1

7 Ley 27287 , artículo 72.1 b)

8 Ley 27287, artículo 78.3.- El título valor que contenga la constancia señalada en el primer párrafo, que será devuelto al interesado al día subsiguiente al de la notificación, con indicación, de ser el caso, del pago parcial que se hubiera hecho, es título suficiente para ejercitar las acciones cambiarias, sin que sea necesario acompañar constancia alguna. 
Notario, obviamente) como dispone expresamente el artículo 78.1 de la Ley de Títulos Valores; por lo que la fecha que la Ley exige poner en el título protestado, además de la cláusula o leyenda de "Documento Protestado" es la fecha en la que se cursó la notificación, y no la fecha en la que se hace la devolución del título protestado, que es facultativa y no impuesta por la Ley. $Y$ es que el protesto se cumple con la notificación y no con la devolución del título, como expresamente lo señala el artículo 74.1 de la Ley de Títulos Valores, al disponer que "El protesto será efectuado mediante notificación dirigida al obligado principal (...)", razón por la cual la Ley solo se ocupa de las prórrogas de la fecha límite para hacer entrega del título al Notario y de la fecha límite para que el Notario dirija la notificación al deudor, como podemos apreciar de lo dispuesto en el artículo $75.2^{9}$ de la Ley 27287 . Ni este numeral ni otro prevén prórrogas de plazos para hacer la entrega en devolución, ni obligación de consignar la fecha en que se realiza tal entrega en devolución del título ya protestado, siendo lo importante la fecha en que se cursa la notificación al deudor, que es el acto cuyo cumplimiento está sujeto a los plazos que fija el artículo 72. Así, podría inclusive extenderse en la práctica el plazo total en el que se cumple válidamente el protesto a plazo mayor a 15 días, siempre que el décimo quinto día resulte sábado, domingo o feriado, en cuyo caso la notificación podrá bien practicarse en fecha posterior al décimo quinto día del vencimiento del título objeto de protesto; tal sería por ejemplo el caso de título valor cuyo décimo quinto día posterior a su vencimiento resulte ser un día sábado, en cuyo caso bien podría el Notario cursar la notificación del protesto el día lunes siguiente, que es el día hábil siguiente y décimo sétimo día posterior al vencimiento, retener hasta el décimo octavo y recién entregar el título protestado en devolución el décimo noveno día posterior a su vencimiento, consignando como fecha de la notificación el décimo sétimo día, tal como lo permite expresamente el ya citado artículo 75.2 de la Ley de Títulos Valores.

Finalmente, la reciente Ley del Notariado aprobado por Decreto Legislativo 1049, prevé en sus artículos 75 al 77, el Registro de Protestos, señalando que los protestos deben ser registrados por los Notarios "(...) asignando una numeración correlativa a cada título según el orden de presentación por parte de los interesados para los fines de su protesto, observando las formalidades señaladas en la ley de la materia", que no son otras que las indicadas en los mismos términos por el artículo 78.1 de la Ley de Títulos Valores, sin que se exija registrar el día o fecha de la devolución del título protestado, sino solo la fecha en la que el Notario curse la notificación al deudor, constancia que debe dejarse en el mismo titulo protestado con refrendo de la firma del Notario por mandato expreso de la Ley, fecha que no puede ser posterior a los plazos que fija el artículo 72 de la Ley de Títulos Valores para el protesto, siendo voluntario y accesorio que además se consigne la fecha de la devolución del título protestado al interesado que lo solicitó, fecha esta que puede estar dentro o fuera de los plazo previstos para el protesto.

9 Ley de Títulos Valores, artículo 75.2.- Si el último día del plazo dentro del cual debe efectuarse la entrega del título al fedatario o verificarse la notificación del protesto fuere día feriado, sábado o domingo; o, en el caso de título valor pagadero con cargo én cuenta mantenida en una empresa del Sistema Financiero Nacional, dicho último día fuese no laborable en la empresa designada, el término queda prorrogado hasta el primer día hábil o, en su caso, día laborable siguiente, siempre que se trate de los días señalados en el párrafo anterior. Los días intermedios feriados, sábado o domingo y, en su caso no laborables, se consideran parea el cómputo del plazo. 